\title{
Research of suitability area of agriculture in Coastal CHAOUIA by integration the AHP, IDW, and MCDA to GIS.
}

\author{
Hanane Souidi ${ }^{1,}{ }^{*}$, Latifa Ouadif ${ }^{1}$, Lahcen Bahi ${ }^{1}$, RaounakEdderkaoui ${ }^{2}$ Imane Jaouda ${ }^{1}$, Iassine Bahi $^{1}$, Siham Belhaj ${ }^{1}$ \\ ${ }^{1}$ 3GIE Laboratory, Mineral Engineering Department,Mohammadia Engineering School, Mohammed V University, Rabat BP 765, \\ Morocco \\ ${ }^{2}$ Hydraulic Systems Analysis Team (EASH), Civil Engineering Department,Mohammadia Engineering School, Mohammed V \\ University, Rabat BP 765, Morocco
}

\begin{abstract}
Agricultural expansion in developing countries requires a strategy to develop the agricultural sector in a sustainable and rational manner, despite its complexity to be achieved. The objective of this work is to develop an agricultural Suitability map, based on a flexible and interactive model between several methods, which are the analytical hierarchy process (AHP), the Inverse Distance Weighting (IDW), and the multi-criteria decision analysis (MCDA),integrated into the GIS. The factors selected in this study are slope, elevation, land use, minimum and maximum temperature, also rainfall for both the dry and rainy periods. The analysis of the suitability map revealed the effectiveness of this model, which allowed the detection of areas unsuitable for agricultural development. the Comparison of the suitability map with the 2019 classified map shows that agricultural expansion is highly developed and covers almost the total area, which has had negative consequences on the groundwater quality of the Coastal CHAOUIA aquifer.
\end{abstract}

\section{INTRODUCTION}

Agricultural development and rural activities play a necessary role in making villagers self-sufficient, as well as in satisfying the food needs of the population[1]. Agricultural expansion requires a strategic study to develop this sector in a sustainable and rational way to achieve the sustainable development goals 2-6 and 15 (SDO) of the United Nations on the horizon of 2030[2].The problems of agricultural policy making in developing countries are generally complex. Many factors can be important: international relations, the role of the state, price policy, land property, credit systems, capital investment, new farming methods, means of transport and storage, traditional experiences, risk perception, etc [3]. The agricultural operational research models are based on traditional research models that may ignore important qualitative factors in their decisions. In developing countries, the problems of making the right decisions are either related to data availability or access to data, this problem is related to the means to maintain a high-quality collection of agricultural statistics[4].

The main objective of the study is to create a model to determine the suitability of agricultural development in the coastal CHAOUIA for better agricultural policy. This model is based on the integration of theInverse Distance Weighting (IDW), the Multicriteria Decision analysis (MCDA) and the Analytical Hierarchy Process (AHP) to GIS. This research applied a series of criteria (temperature, rainfall, slope, altitude, land use), to establish the map of suitability for agriculture in the Coastal CHAOUIA.

\section{STUDY AREA}

The Coastal CHAOUIA covers an area of $1120.7 \mathrm{~km}^{2}$, between the cities of Casablanca and Azemmour (Fig1).it presents an important axe of Casablanca-Settat region in terms of agricultural production on one hand, and animal production on the other hand. The climate of the region is of the meridional Atlantic type. The rainfall and temperature are moderate, if the winter is mild and wet, the summer is hot and dry[3].

The Coastal CHAOUIA aquifer is an important groundwater reservoir in the province, but currently its quality is in a deteriorated state. In fact, the strong agricultural and agro-industrial activities generate an excessive exploitation of water resources.This latter causes various problems of pollution, mainly by pesticides and fertilizers, as well as salinity of water through intense drainage for irrigation[5].

'Corresponding author:souidihanane@gmail.com 
Fig 1.Study Area location Map[5]

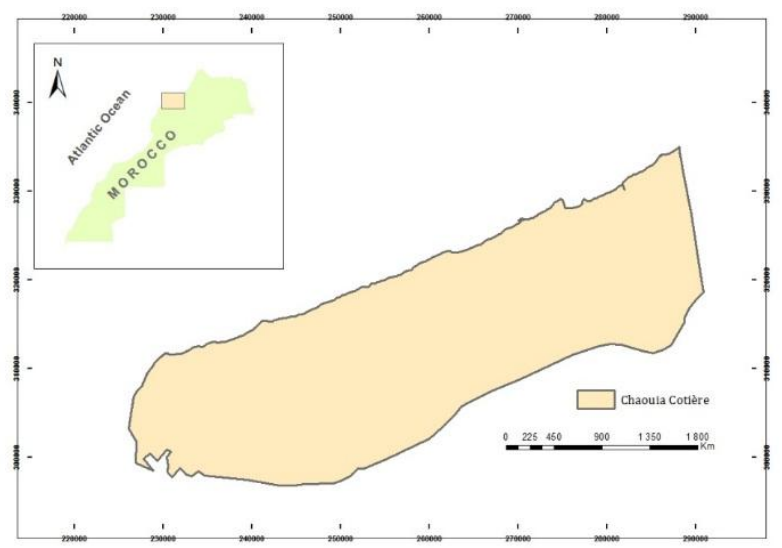

\section{MATERIALS AND METHODS}

\subsection{Impact Factors for the Suitability of agriculture}

\subsubsection{Temperature and Rainfall}

The temperature and rainfall data are extracted from the site web[6]over a period of 32 years, from 1987 to 2018 in format csv. Theinterannual temperature and rainfall data are processed using GIS by the IDW interpolation method. Four maps have been obtained of minimum and maximum average temperature maps of the dry period and rainy periods.In addition, for rainfall factor, two maps have been realised in the rainy and dry periods. Also, the realization of the data of average Ombrothermic diagram was done to determine the dry and rainy period for 32 years. The rainfall data block obtained to summarize variations in average rainfall in order to understand the rainfall pattern in this area.

\subsubsection{Slope and Elevation}

The topographic information was obtained from the data of digital elevation model (DEM), with a resolution of $10 \mathrm{~m}[7]$. Then, the slope and elevation were extracted by using GIS techniques. The slope has been divided into three classes, $0-5^{\circ}, 5-15^{\circ},>15^{\circ}$. While the elevation has been classified in five categories: $<25 \mathrm{~m}, 25-50 \mathrm{~m}, 50$ $100 \mathrm{~m} \mathrm{100-150}$ and 150-205 m.

\subsubsection{Land use}

In this study, four satellite images (Table 1) were selected. The choice of these images is based on the availability of the images during the month of January and the total coverage of the study area. The maximum likelihood classification method was applied to these images, which were classified by selecting specific polygons. Five classes were used, namely water, forest, farmland, building and bare ground class.

Table 1. Satellite imagery used[5]

\begin{tabular}{|c|c|c|}
\hline Sensor type & Acquisition date & $\begin{array}{c}\text { Spatial } \\
\text { resolution }\end{array}$ \\
\hline Landsat4-5tm & $06 / 01 / 1987$ & $30 \mathrm{~m}$ \\
\hline Landsat4-5tm & $07 / 01 / 1999$ & $30 \mathrm{~m}$ \\
\hline Landsat4-5tm & $08 / 01 / 2011$ & $30 \mathrm{~m}$ \\
\hline Landsat-8 oli/tirs & $18 / 01 / 2019$ & $30 \mathrm{~m}$ \\
\hline
\end{tabular}

\subsection{Analytical Hierarchy Process (AHP)}

The AHP has been developed by Thomas Saaty. It is a multi-criteria decisionmaking technique that breaks down a complex problem into a hierarchy, in which each level is composed of specific elements[8]. The AHP methodology is used to determine the most consistent alternative with our criteria, based on the level of importance obtained for the different criteria and by considering our comparative judgements[9]. The calculation of the weighting factors of $\mathrm{n}$ input elements consists in comparing each pair of elements using the following scale[10]:

$$
\mathrm{W}=\left[\mathrm{W}_{\mathrm{i}} / \mathrm{w}_{\mathrm{j}}\right]=\left[\begin{array}{ccc}
\mathrm{W}_{1} / \mathrm{W}_{1} & \ldots & \mathrm{w}_{1} / \mathrm{w}_{\mathrm{n}} \\
\vdots & \cdots & \vdots \\
\mathrm{w}_{\mathrm{n}} / \mathrm{w}_{1} & \cdots & \mathrm{w}_{\mathrm{n}} / \mathrm{w}_{\mathrm{n}}
\end{array}\right]
$$

The pairwise comparison of element $i$ with element $j$ is placed in the aij position of the pairwise comparison matrix $\mathrm{A}$ as shown below:

$$
\mathrm{A}=\left[\mathrm{a}_{\mathrm{ij}}\right]=\left[\begin{array}{ccc}
1 & \mathrm{a}_{\mathrm{lj}_{\mathrm{j}}} & \mathrm{a}_{\mathrm{ln}} \\
1 / \mathrm{a}_{\mathrm{lj}} & 1 & \mathrm{a}_{\mathrm{in}} \\
1 / \mathrm{a}_{\mathrm{ln}} & 1 / \mathrm{a}_{\mathrm{in}} & 1
\end{array}\right]
$$

The aij elements estimate the ratios wi/wj where $\mathrm{w}$ is the vector of current weights of the alternative.

$$
\mathrm{A}_{\mathrm{W}}=\mathrm{x}_{\max } * \mathrm{~W}
$$

With $\lambda \max$ : eigenvalue.

The consistency index (CI) as follows:

$\mathrm{CI}=\frac{\min _{\mathrm{m} x}-\mathrm{n}}{\mathrm{n}-1}$

A consistency ratio is taken as the ratio of the consistency of the results tested to the consistency of the same problem assessed with random numbers. This report provides the user with a value that can be used to 
judge the relative quality of the results. If a consistency ratio of less than 0.10 is obtained, the results are sufficiently accurate and there is no need for further evaluation. However, if the consistency ratio is greater than 0.10 , the results may be arbitrary and preferences must be reassessed,defined the consistency ratio (CR) as[10]:

$$
\mathrm{RC}=\frac{\mathrm{CI}}{\mathrm{RI}}
$$

Average random consistency indexes random index (RI) of the judgement matrix[10]:

\begin{tabular}{|l|c|c|c|c|c|c|c|c|c|}
\hline $\mathbf{n}$ & 1 & 2 & 3 & 4 & 5 & 6 & 7 & 8 & 9 \\
\hline $\mathbf{R I}$ & 0 & 0 & 0.58 & 0.90 & 1.12 & 1.24 & 1.32 & 1.41 & 1.45 \\
\hline
\end{tabular}

\subsection{The Inverse Distance Weighting (IDW)}

Theinverse distance weighting interpolation (IDW) determines the cell values via the linearly weighted combination of a set of sampling points. Weighting is an inverse function of distance. The area that is interpolated must be that of a location-dependent variable. This method assumes that the influence of the tracer variable decreases with distance from the sampled location[11][12]. Inverse distance interpolation (IDW) is a good imputation method because it takes into consideration the weight of the stations[13]. The equation would be as:

$\mathrm{P}_{0}=\sum_{\mathrm{i}=1}^{\mathrm{n}} \frac{\mathrm{P}_{\mathrm{i}}}{\mathrm{D}_{\mathrm{i}}} \sum_{\mathrm{i}=1}^{\mathrm{n}} \frac{1}{\mathbb{P}_{\mathrm{i}}}$

$\mathrm{P}_{0}$ is the estimated value of the missing data. $P_{i}$ is the value of the same parameter at the nearest station i on a given date. $d_{i}$ is the distance between the surrounding stations and the station in question, and $n$ is the number of the neareststations.

\section{4 the Multicriteria Decision Making Analyse (MCDA)}

Multi-criteria decision analysis (MCDA) is a subdiscipline of operational research that explicitly assesses multiple conflicting criteria in decision making. This step includes standardization, weighting calculation and summary analysis of all criteria considered in the decision-making process.

\section{ANALYSIS AND DISCUSSION}

\subsection{Amount of land use changes observed}

The results of the analysis of land use change are presented in Table 2. During the period 1987-1999, about $45.4 \mathrm{~km}^{2}$ of forests and $0.1 \mathrm{~km}^{2}$ of water were transformed into $28 \mathrm{~km}^{2}$ agricultural areas, $0.9 \mathrm{~km}^{2}$ into buildings and $17.4 \mathrm{~km} 2$ into bare soil. Between the period 1999-2011 we notice that there is a transfer of $12 \mathrm{~km}^{2}$ of bare soil and $0.5 \mathrm{~km}^{2}$ of forests in $9 \mathrm{~km}^{2}$ of agricultural land, $2.9 \mathrm{~km}^{2}$ in buildings and $0.6 \mathrm{~km}^{2}$ in water, In addition, between 2011-2019 the bare land is transferred to agricultural land with an area of $10.3 \mathrm{~km}^{2}$ followed by forests $6.3 \mathrm{~km}^{2}$, buildings $2.3 \mathrm{~km}^{2}$ and water $0.3 \mathrm{~km}^{2}$. The total loss of forest area during these 32 years reaches almost $501.1 \mathrm{~km}^{2}$, which has been transformed mainly to agricultural areas by an area of $526.7 \mathrm{~km}^{2}$, which is considered as a very significant land-use change over a short period of time. In addition, the surface area of the buildings itself increased by 64.8 $\mathrm{km}^{2}$, followed by a decrease of $88.6 \mathrm{~km}^{2}$ in the surface area of the bare ground. However, this remarkable rate of land use change from forest to agricultural and urban areas raises many questions about agricultural growth patterns in the CHAOUIA Coastal area, the overexploitation of water resources, as well as the intense degradation of the quality of the waters of the coastal CHAOUIA aquifer and the salinity of the fresh water of the aquifer, in addition to the sustainable environmental policies and regulations monitored and applied in the study area[5]. 
Fig 2. Land use maps in different years[5]: (a) 1987, (b) 1999, (c) 2011, (d) 2019
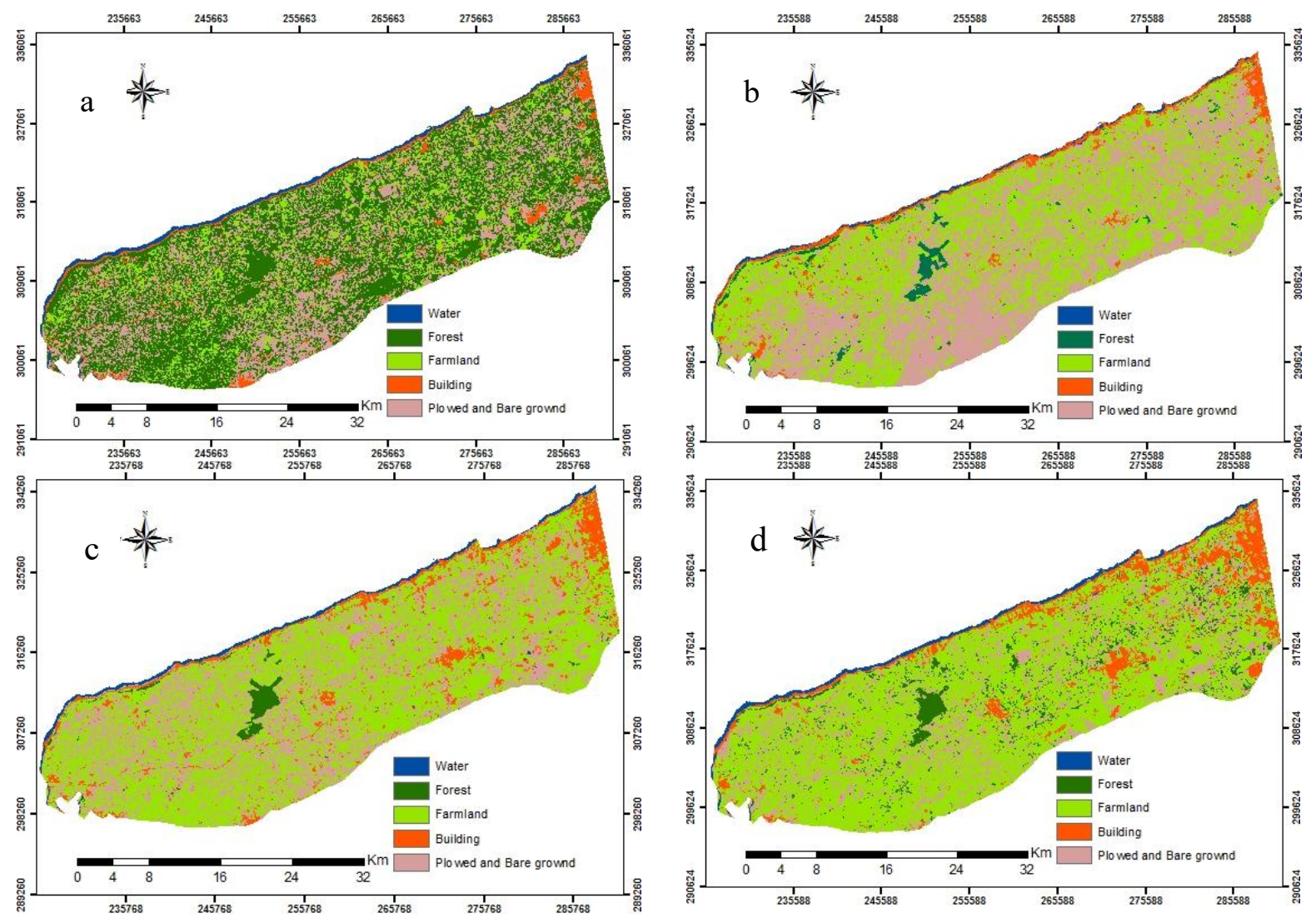

Table 2.Amount of land use changes observed $\left(\mathrm{km}^{2}\right)[5]$

\begin{tabular}{|c|c|c|c|c|c|}
\hline & Water area & Forest area & Farmland area & Building area & $\begin{array}{l}\text { Plowed and Bare } \\
\text { ground area }\end{array}$ \\
\hline 1987 & 24.5 & 569.3 & 169.2 & 42.9 & 314.8 \\
\hline 1999 & 12.9 & 24.3 & 505.6 & 54.2 & 523.8 \\
\hline 2011 & 20.4 & 17.9 & 613.5 & 89.2 & 379.7 \\
\hline 2019 & 22.7 & 68.2 & 695.9 & 107.7 & 226.2 \\
\hline Annual change 1987-1999 & -1.0 & -45.4 & 28.0 & 0.9 & 17.4 \\
\hline Annual change 1999-2011 & 0.6 & -0.5 & 9.0 & 2.9 & -12.0 \\
\hline Annual change 2011-2019 & 0.3 & 6.3 & 10.3 & 2.3 & -19.2 \\
\hline Total change & -1.8 & -501.1 & 526.7 & 64.8 & -88.6 \\
\hline
\end{tabular}

\subsection{Analysis of climatological factors: temperatures and rainfall}

Various meteorological factors can interact to influence plant ecophysiological responses, such as the growth, frequency and timing of rainfall pulses[14].The intra- annual rainfall patterns, in particular the seasonal distribution of rainfall, are recognized as governing functional and species diversity [3]. Over a period of 32year(1987-2018), an average ombrothermic diagram (Fig.3)has been established, showing that the dry period (From April to October) is very long,which the average amount of rainfall is very low $(<40 \mathrm{~mm})$. The rainy period 
has average rainfall between $40 \mathrm{~mm}$ and $70 \mathrm{~mm}$ with a shorter period from November to March.

Analysis of the maps (Fig.4. (e) and (f)) indicates that, as it moves from the northeast to the southwest of the study area, the average amount of rainfall decreases during the dry and rainy periods.

The figure 6 summarizes a block of rainfall data for 32 years. The latter allows us to observe that the rainfall regime is irregular, so the amount of rainfall is poorly distributed over time and space(Fig4). The graph at the bottom of the rainfall data block, allows us to know the wettest months (November, December, January) and dry months (July, August). The graph on the right presents the cumulative rainfall for each year. The area study has known many years of dryness.In the middle of the block (fig 6), the degradation of the blue color shows that more and more the color becomes clear the rainfalldecreases.

The temperature is one of the climate factors that directly affects the vital functions of the plant and the speed of biological processes. A metabolic activity takes place in a specific temperature range. Plants can grow in a wide range of temperatures; hence the temperature limits change with plant adaptation in different ecological zones. The different types of plants have different minimum and maximum temperature points above these values the plant stops growing [15].

In view of the importance of these two parameters, we determined the average minimum temperature (Tmin) in two periods (dry and rainy), (Fig.5. (h) and (j))as well as the average maximum temperature (Tmax) (Fig.5. (g) and (i)). The analysis of the maps shows that: during the rainy period, the two average temperatures (Tmin and Tmax) decrease gradually from northeast to south and southwest (Fig.5. (i), (j)). Whereas, in the dry period, the average minimum temperature and average maximum temperature increase gradually from north east to southwest(Fig.5. (g), (h)).

The average ombrothermicdiagram(Fig.3) shows thatthe average temperature value of the coldest month is $15^{\circ} \mathrm{C}$, and the warmest month is $25^{\circ} \mathrm{C}$.

The analysis of climatic factors allows us to say that the coastal CHAOUIA area has a semi-arid climate with a moderately warm winter. The temperature in this area is very suitable for plant growth.On the other hand, rainfall is low to cover water needs in agriculture.

Fig 3. Average Ombrothermic Diagram (1987-2018)

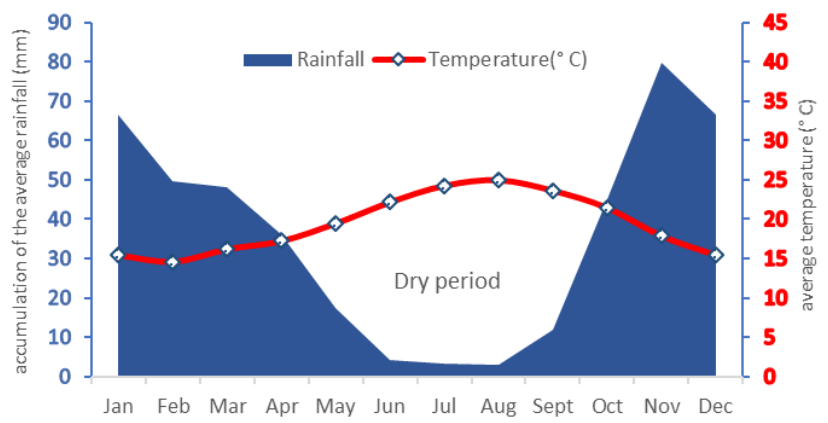

Fig 4. Average rainfall: (e) in dry period, (f) in rainy period
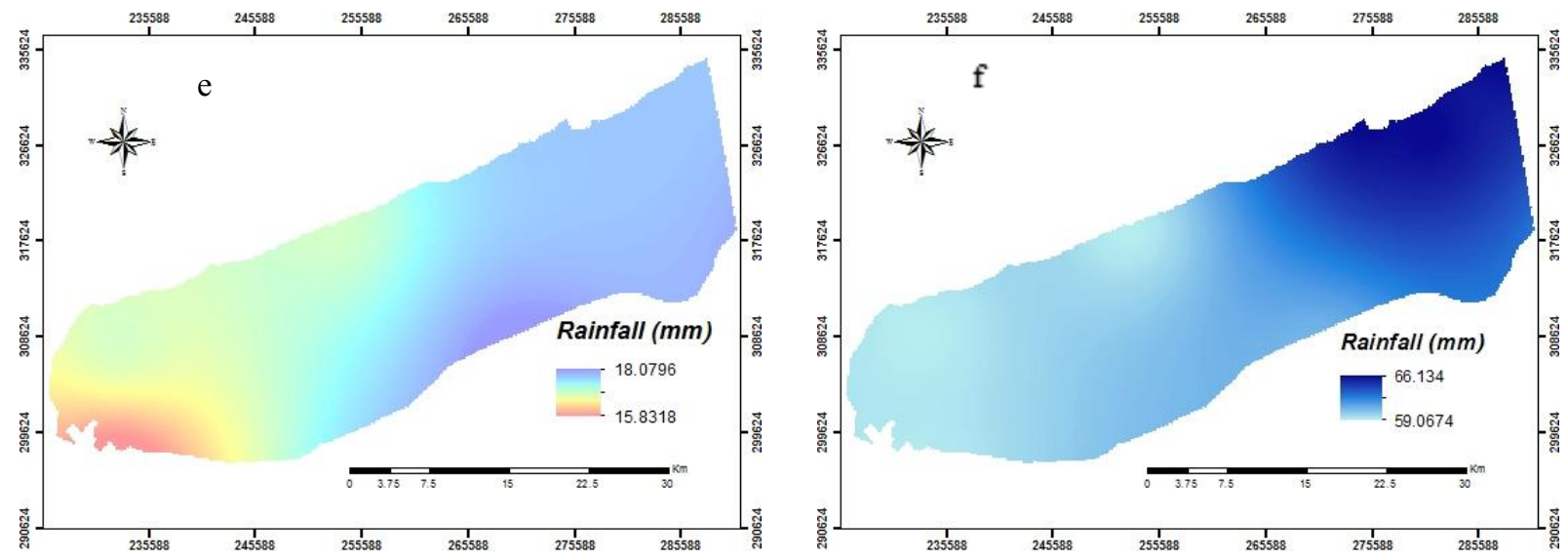
Fig 5. Average Temperature: (g) Tmax in dry period, (h) Tmin in dry period, (i) Tmax in rainy period, (j) Tmin in rainy period
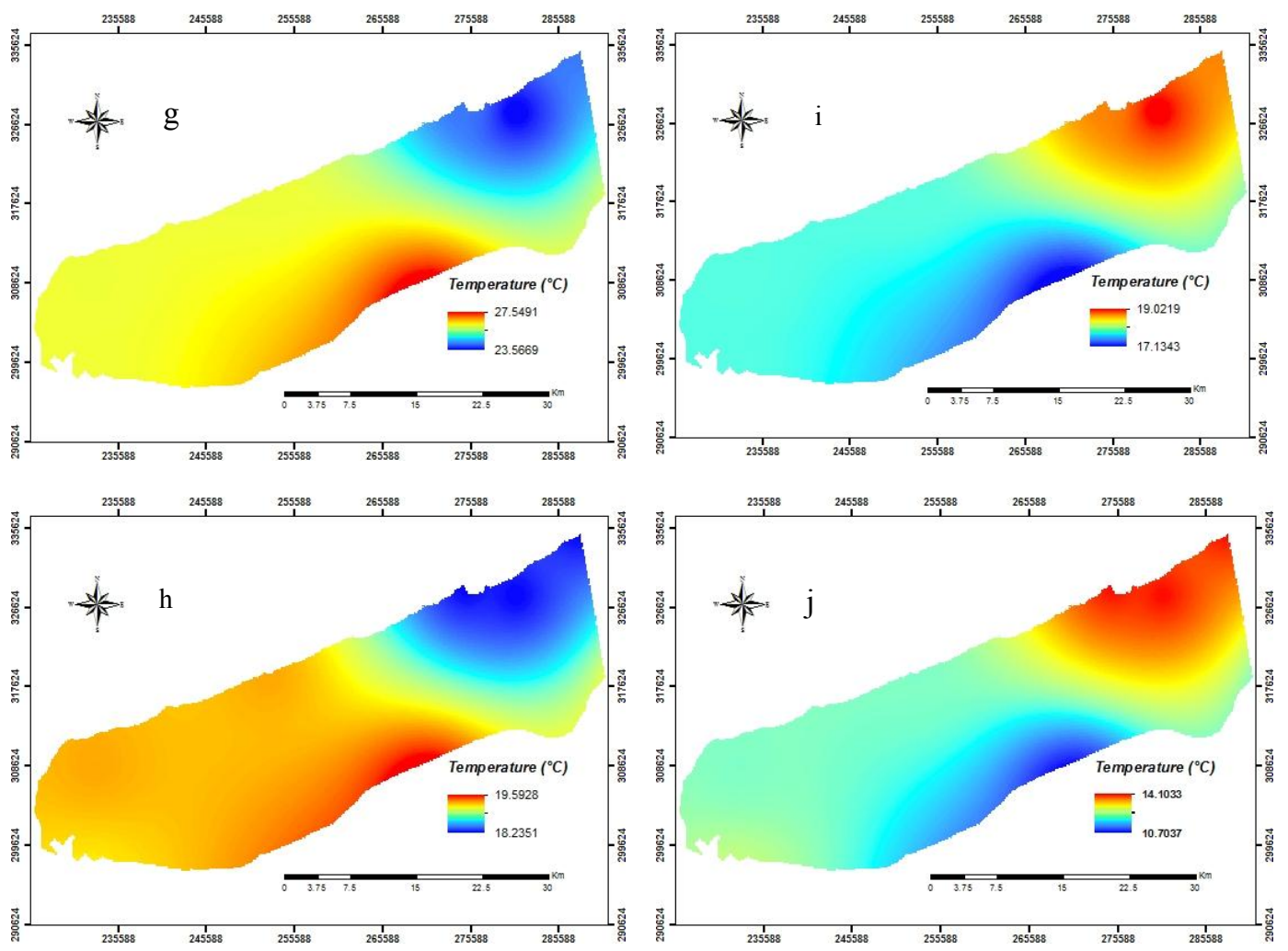

Fig 6.Rainfall data block (1987-2018)

\subsection{Analysis of topological factors: slope and elevation}

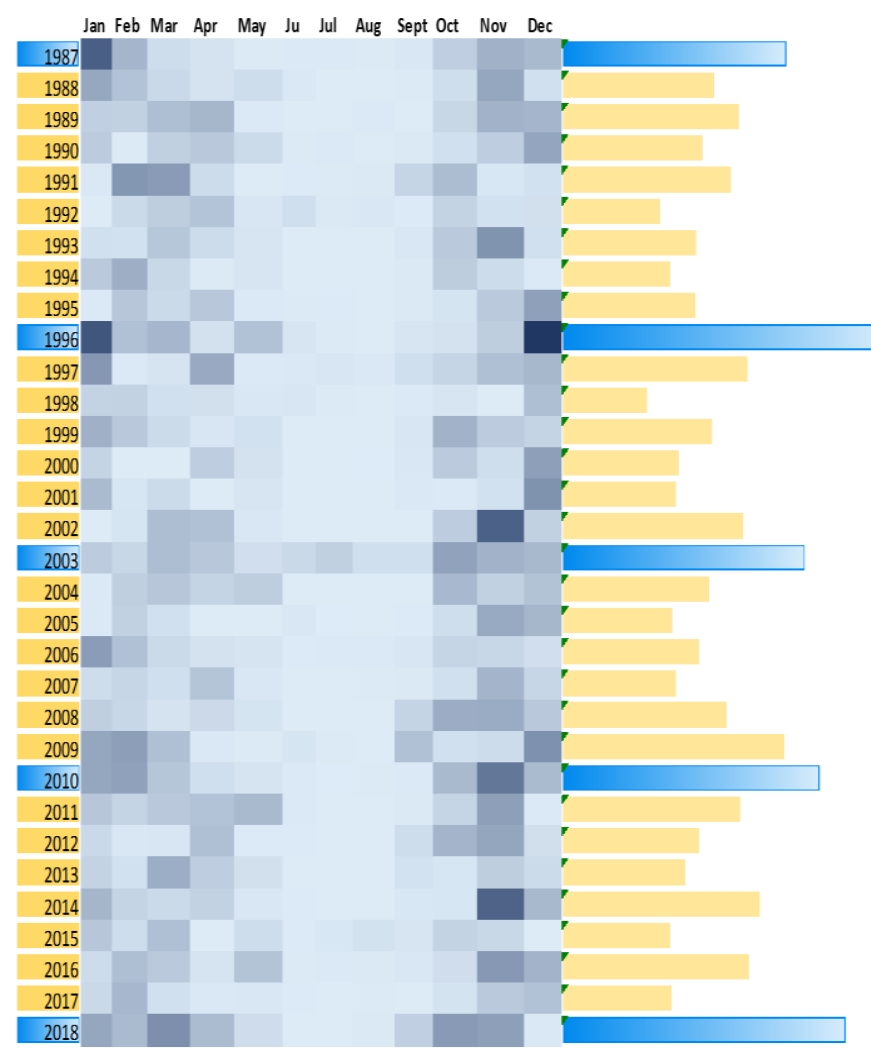

Slope and elevation are also important topographic factors in assessing agricultural selection suitability. Sloping land is often subject to erosion, resulting in soil degradation. The Fig 7 shows that the coastal CHAOUIA area is considered slightly inclined, as most areas have a slope of less than $5^{\circ}$ or between $5^{\circ}-15^{\circ}$. This parameter makes several types of agriculture favourable. The optimal slope for the agricultural was $0-5^{\circ}[16]$.

The elevation map (Fig8) shows that going from south to north, the elevation of the land decreases by $205 \mathrm{~m}$ until it reaches zero or negative values as it approaches the Atlantic coast. The area is then considered almost plain. The potential production of cultivated land in areas $<100$ m is very high, between $100-200$ m the productivity is average good and beyond these values, the production decreases gradually with the elevation of land[16]. 
Fig 7. Slope map

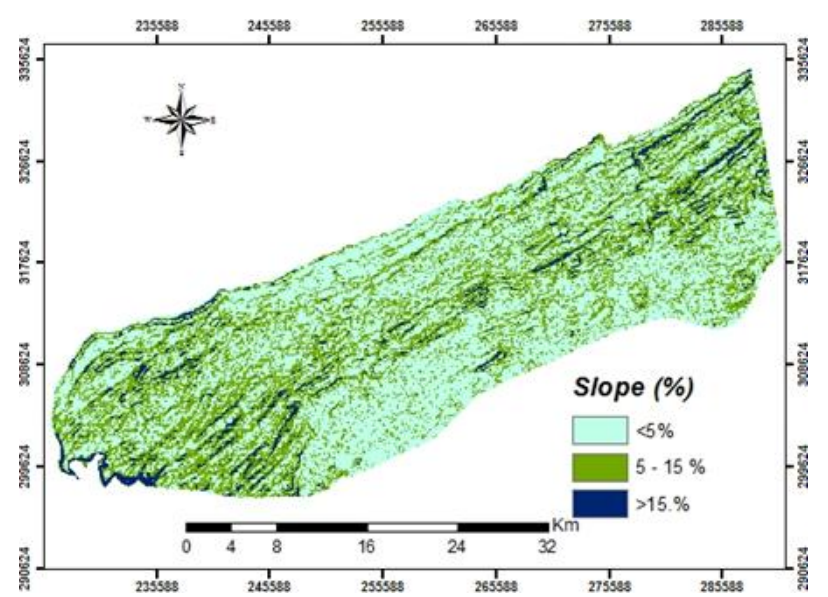

Fig.8. Elevation map

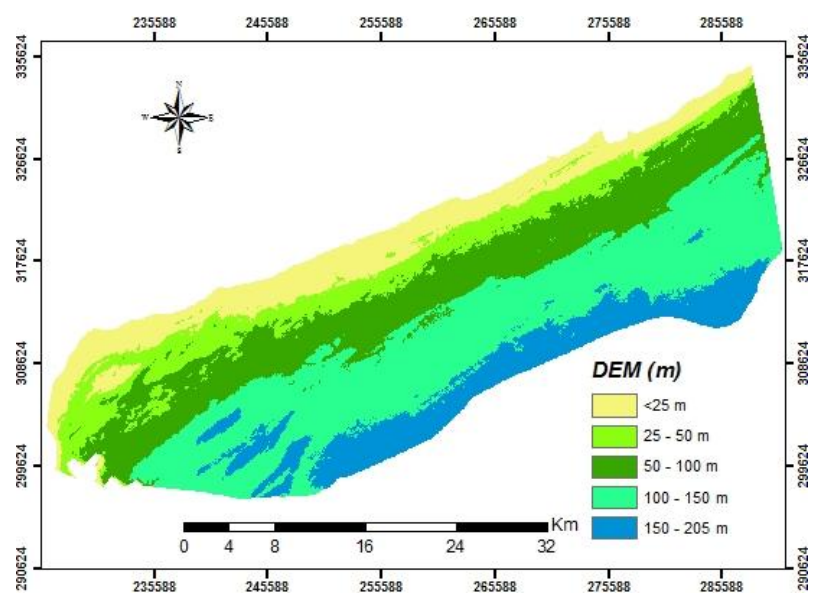

\subsection{Analysis of the aptitude map}

Parameter modelling by the AHP analytical hierarchy process method is used to calculate the weights of each selected factor. Table 1 shows the factors and their weights. The rainfall weight during the rainy period is the highest 0.1913 , and the land use weight is the lowest 0.0344 . Table 2 summarizes the calculated parameters from the AHP matrix. The RC coefficient obtained is 0.1 , which provides an acceptable value, indicating that the matrix performed is within the standards. The weighted superposition method allowed the creation of the aptitude map for agriculture. According to the analysis of this map, going from south-east to north-west the suitability of the land for agriculture decreases, at the extremity of the coastal areas, the land is not suitable for agricultural practice.
Table 4.values of AHP settings

\begin{tabular}{|c|c|}
\hline factors & Value \\
\hline $\mathrm{n}$ & 9 \\
\hline $\mathrm{mmax}$ & 10.16 \\
\hline $\mathrm{CI}$ & 0.145 \\
\hline $\mathrm{RC}$ & 1.45 \\
\hline $\mathrm{CR}$ & 0.1 \\
\hline
\end{tabular}

Table 5Weight of factors

\begin{tabular}{|l|l|}
\hline \multicolumn{1}{|c|}{ Factors } & Weight \\
& \\
\hline Elevation & 0.0227 \\
\hline Slope & 0.0627 \\
\hline Land use & 0.0344 \\
\hline dry period & 0.1130 \\
\hline Tmax in dry period & 0.1486 \\
\hline Tmin in dry period & 0.1283 \\
\hline Tmax in rain period & 0.1446 \\
\hline Tmin in rain period & 0.1545 \\
\hline Rainy period & 0.1913 \\
\hline
\end{tabular}

\subsection{Discussion of the results:}

In this study, the soil parameter was not considered because the soil texture of the coastal CHAOUIA is of the sandy-limoney type. The $\mathrm{pH}$ is almost similar in the different parts of the area $(\mathrm{pH} 8.17)$. The presence of organic matter makes the soil more stable, hence the positive correlation that promotes the protection of the soil against leaching[17].

Topographical parameters are essential for agricultural productivity, the stability of fertile soils, and become very favourable in an area with a low slope and altitude.

The temperature is influenced by marine currents; in fact, the coastal climate is moderately hot and dry in summer, and relatively mild and rainy in winter. The temperature in this area does not present the limiting factor for agricultural practice.

Rainfall is very low when compared to agricultural production. Land use maps from 1987 to 2019 have shown that land use change is directed towards agricultural expansion. The aptitude map revealed the areas unsuitable for agriculture, which are in fact cultivated mainly by nearing the coastal margin which explains the pollution and salinity of the coastal CHAOUIA groundwater. Indeed, pollution is due to intensive agricultural activity that uses pesticides. Water salinity is caused by intensive groundwater drainage to compensate for the lack of rainfall and also the use of fertilizers. 
Fig.9.Agricultural Suitability map.

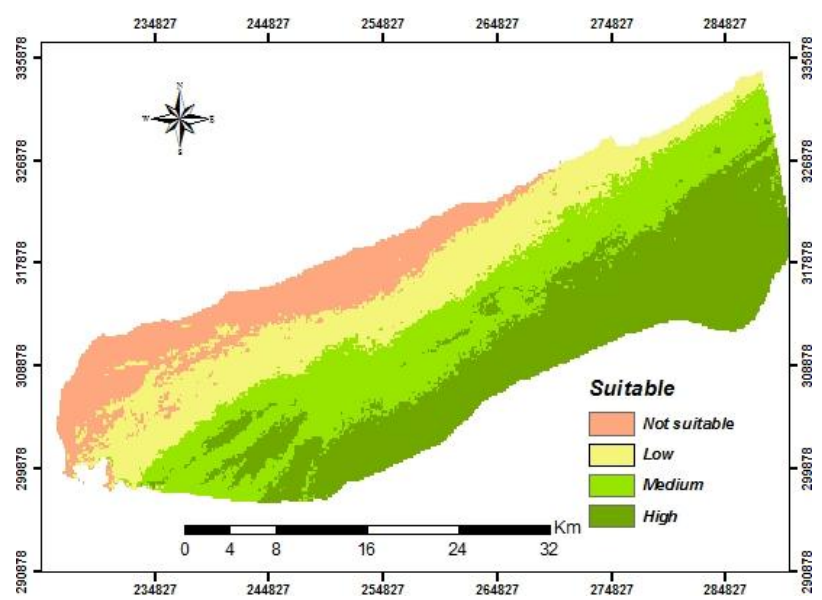

Conclusion

Modelling by AHPand other analytical methods, using GIS, has enabled us to develop an agricultural suitability map.The latter has revealed areas unsuitable for agriculture. The comparison of the suitability map with the 2019 classified map shows that agricultural expansion is highly developed and covers almost the entire area.It has negative consequences for the water quality of the coastal CHAOUIA groundwater. This paper has provided valuable results for estimating the suitability and even the future situation of the area. Research methodology is not only used for agricultural development assessment and zoning, but can also be applied in many different fields.

\section{References}

[1] D. Läpple and J. Cullinan, Ir. Geogr., vol. 45, no. 1, pp. 67-85, (2012).

[2] "Home - 2019 - United Nations Sustainable Development." [Online]. Available: https://www.un.org/sustainabledevelopment/. (Accessed: 18-Nov-2019).

[3] C. Schweigman, E. J. Bakker, and T. A. B. Snijders, Eur. J. Oper. Res., vol. 49, no. 2, pp. 211-221, Nov. (1990).

[4] C. B. Alphonce, Agric. Syst., vol. 53, no. 1, pp. 97-112, (1997).

[5] H. Souidi,L.Ouadif, L.Bahi, and N.Habitou, (IJRTE), vol. 8, no. 4, p. 8, (2019).

[6] "POWER Data Access Viewer." [Online]. Available: https://power.larc.nasa.gov/data-accessviewer/. [Accessed: 18-Nov-2019].

[7] “Accueil | Copernicus." [Online]. Available: https://www.copernicus.eu/fr. (Accessed: 18-Nov2019).

[8] T. L. Saaty, Int. J. Serv. Sci., vol. 1, no. 1, p. 83, (2008).

[9] E. Mu and M. Pereyra-Rojas, Practical Decision Making, Cham: Springer International Publishing, pp. 7-22.(2017).
[10] T. L. Saaty, Interfaces, vol. 24, no. 6, pp. 19-43, (1994).

[11] G. M. Philip and D. F. Watson, Math. Geol., vol. 18, no. 1, pp. 93-117, (1986).

[12] G. M. Philip and D. F. Watson, Int. J. Min. Eng., vol. 3, no. 2, pp. 155-159, (1985).

[13] J. El Kasri, A. Lahmili, O. Latifa, L. Bahi, and H. Soussi, (AI2SD'2018)Springer International Publishing, vol. 913, pp. 13-21. (2019).

[14] K. Ogle and J. F. Reynolds, Oecologia, vol. 141, no. 2, pp. 282-294, (2004).

[15] M. N. T. Doan et al., in From Science to Society, Springer International Publishing, pp. 1324.(2018).

[16] Y. Li, X. Yang, H. Cai, L. Xiao, X. Xu, and L. Liu, Sustainability, vol. 7, no. 1, pp. 96110.(2014).

[17] F. Rafik, N. Saber, F. Zaakour, H. Mohcine, K. Moustarhfer, and C. Marrakchi, ESJ,vol.11 p. 17, (2015). 